\title{
Statistical Prediction of Summer Rainfall and Vegetation in the Ethiopian Highlands
}

\author{
Mark R. Jury ${ }^{1,2}$ \\ ${ }^{1}$ University of Puerto Rico, Mayaguez, Puerto Rico, PR 00681, USA \\ ${ }^{2}$ University of Zululand, KwaDlangezwa 3886, South Africa \\ Correspondence should be addressed to Mark R. Jury; mark.jury@upr.edu
}

Received 23 October 2013; Accepted 11 February 2014; Published 17 March 2014

Academic Editor: Luis Gimeno

Copyright (c) 2014 Mark R. Jury. This is an open access article distributed under the Creative Commons Attribution License, which permits unrestricted use, distribution, and reproduction in any medium, provided the original work is properly cited.

\begin{abstract}
Year-to-year fluctuations of Ethiopia climate are investigated to develop statistical predictions at one-season lead time. Satellite vegetation data from NASA and rainfall from ARC2 are the basis for analysis. The "target" seasons are May-July and AugustOctober, while "predictors" are December-February and March-May, respectively. Global fields of surface temperature, sea level air pressure, and upper and lower level zonal winds are employed in point-to-field correlations. After step-wise multivariate regression, the leading predictors are: surface temperature across Europe (cold-favourable), $850 \mathrm{mb}$ zonal winds over the tropical Atlantic (easterly-favourable), and surface temperature in the tropical Indian Ocean (cold-favourable). Predictive algorithms for early and late rainfall exhibit a consistent $r^{2}$ fit of $\sim 0.50$, while those for vegetation reach $\sim 0.65$ in late summer, indicating that fluctuations in food resources could be forewarned.
\end{abstract}

\section{Introduction}

Climate variability in Ethiopia directly impacts food resources available to a rural population already experiencing a deficit of $\sim 10^{13} \mathrm{KCAL} / \mathrm{yr}$ [1]. An ability to predict crop yield and improve production requires a technical capacity underpinned with knowledge on how the global circulation affects regional climate. Reliable locally tailored forecasts can help communities to avoid risks, optimize resources, and restrain the macroeconomic impacts of drought and flood [2-8]. These prospects motivate our research.

When climate departs from the expected annual cycle, it is often due to slowly varying surface boundary conditions like the Pacific El Nino Southern Oscillation (ENSO) or its decadal component (PDO). While the tropical ocean thermocline is considered a driver of climate, the atmosphere's hydrostatic response may cause long-lived circulation patterns to slowly propagate around the world, bringing opportunities for climate prediction [9-12]. Coupled ensemble numerical models are becoming more sophisticated in simulating these processes, and their forecasts already provide useful regional guidance a few months before the rainy season [13-15]. Wang and Fan [16] show how both ensemble numerical model predictions and observed spatial patterns in "analog years" can be combined to improve the prediction of east Asian summer rainfall. Yet there is still room for statistical techniques that assume historical replication via multiple regression and more complex techniques [17-22].

The main goals of this study are to develop the ability to statistically predict Ethiopian summer rainfall and vegetation by determining the most influential climate indices, formulating multivariate algorithms and evaluating their reliability. Following this introduction, Section 2 provides the data and methods. Section 3 analyzes the results, while conclusions are given in Section 4.

\section{Data and Methods}

The data and methods employed to develop prediction algorithms for Ethiopia are described. "Targets" include interpolated observed summer rainfall and satellite vegetation fraction, while surface and atmospheric "predictors" are drawn from satellite-era reanalysis products in the preceding season. An earlier study found a significant correlation 

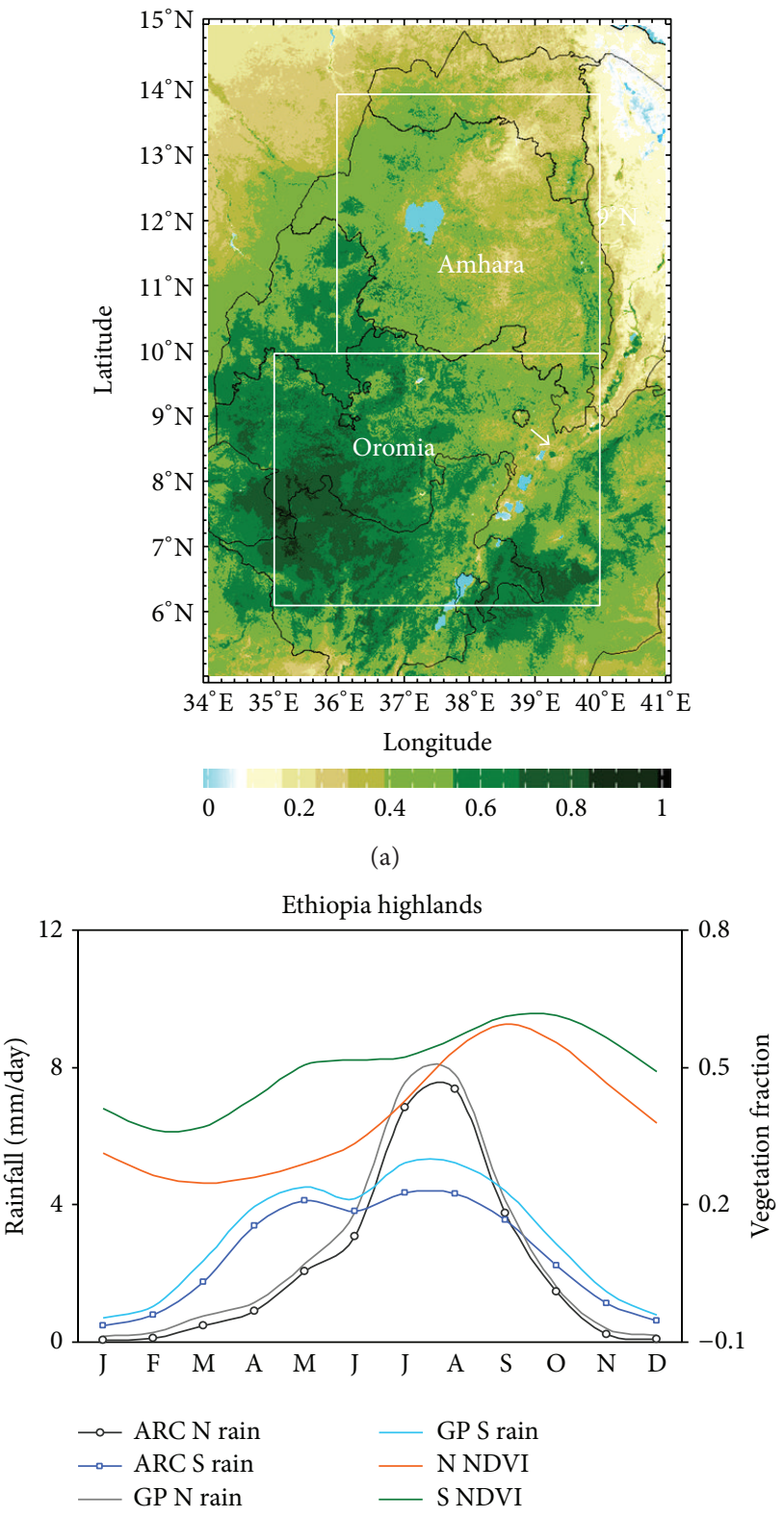

(b)

FIGURE 1: (a) Vegetation fraction averaged 2000-2012 from MODIS, with state boundaries, target boxes and the national experimental farm (arrow). (b) Mean annual cycle of ARC2/GPCC6 rainfall and vegetation NDVI 1981-2006.

$(r=0.56)$ between colocated vegetation fraction in JulySeptember and harvested maize and sorghum yields in the period 1986-2009 [23].

2.1. Target and Predictor Data. Gridded monthly rainfall data for Ethiopia were analyzed from the African Rainfall Climatology (ARCv2, [24]). A secondary dataset was derived from the Global Precipitation Climatology Center (GPCCv6, $[25,26])$. Their respective resolutions/temporal coverages are $10 \mathrm{~km} / 1983-2012$ and $50 \mathrm{~km} / 1981-2010$. Comparisons with

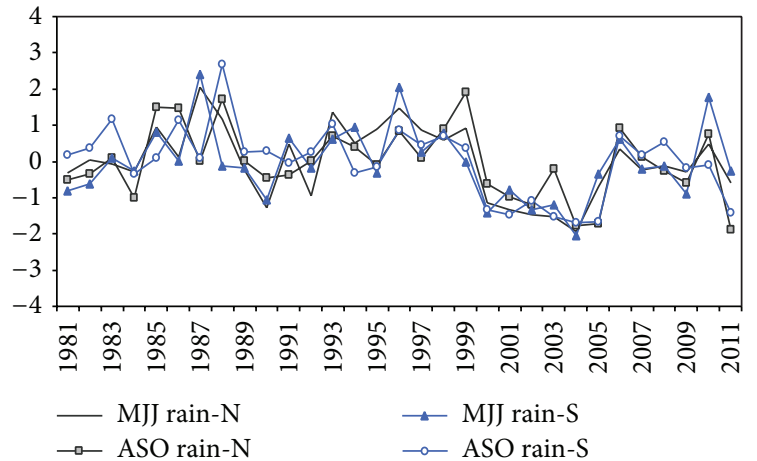

(a)

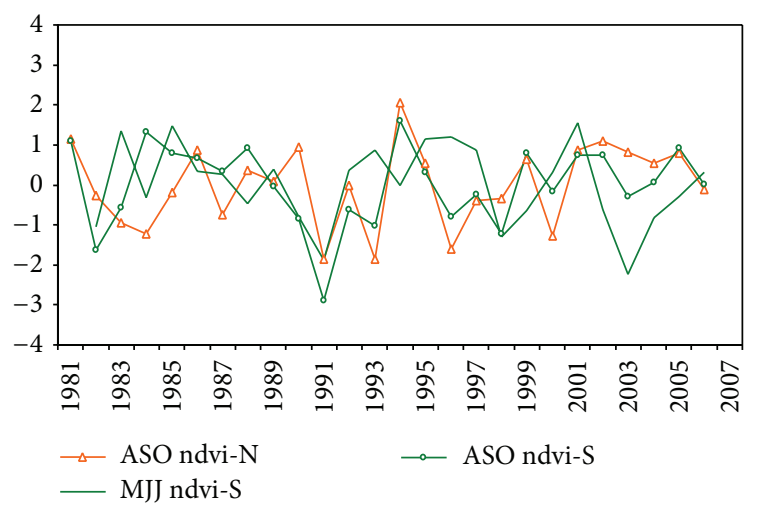

(b)

FIGURE 2: Standardized departures of (a) rainfall and (b) vegetation fraction for two zones in two seasons (MJJ NDVI omitted in north).

gauges from the Ethiopian National Meteorological Agency yielded better performance by ARC2. Vegetation fraction values originate from the corrected NASA satellite dataset (NDVI, [27]) at $25 \mathrm{~km}$ resolution in the period 1981-2006. Instead of using objective analysis to define target areas [28], crop productivity reports from the Ethiopian Central Statistical Agency (http://www.csa.gov.et/) suggest two main zones in the northern and southern highlands: $10-14 \mathrm{~N}$, 36-40E Amhara and 6-10N, 35-40E Oromia, identified in Figure 1(a). The rainy season is divided into the first and second half (May-July, August-October) hereafter MJJ and ASO. The targets are of sufficient size for averaging to damp out local "noise", yet they still fall within a homogeneous climate regime [29]. Considering the mean annual cycle (Figure 1(b)), rainfall in the south rises in May while vegetation in the north peaks in September. Hence early (late) summer forecasts are critical to strategic planning in Oromia (Amhara). Linear trend analysis indicates no significant drift in the target records over the period since 1981 (Figure 2). Target data were drawn from the IRI Climate Library (ARC2) and Climate Explorer websites (GPCC6, NDVI).

The predictor fields employed here include global landsea surface air temperature from the National Climate Data Center v3 (Ts, [30]), sea level air pressure from the Hadley Center v2 reanalysis (SLP, [31]), and $850 \mathrm{mb}$ and $200 \mathrm{mb}$ zonal winds from Coupled Forecast System (CFS) and 
NASA Modern Era (MERRA) reanalysis [32, 33]. Seasonal averages were calculated: December-February (DJF) for MJJ targets and March-May (MAM) for ASO targets. Predictor fields were available from the Climate Explorer website $\langle\mathrm{http} / / /$ climexp.knmi.nl/〉 and analyzed globally in latitudes $50 \mathrm{~S}-60 \mathrm{~N}$.

2.2. Methods. Our search for predictors was facilitated by linear point-to-field correlation analysis followed by stepwise multivariate regression of key-area time series. Correlation maps were calculated for the specified predictor-target lead time (e.g., DJF for MJJ, MAM for ASO) and fields were masked below $80 \%$ significance. For selection as a predictor, the key area should exceed $15^{\circ}$ latitude $\times 20^{\circ}$ longitude in size. All time series were converted to standardized departures (cf. Figure 2).

Statistical prediction algorithms were formulated via backward stepwise linear regression onto the target time series. The candidate predictor pool was $<10$ compared with a training period of $\sim 30$ years. Initially all predictors were included and their partial correlation was evaluated. Those with lower significance (or colinearity) were screened out and the algorithm was recalculated from the remaining variables. In most cases an optimal fit was reached with three predictors, thereby limiting the chance of artificial skill [6].

A 30 year training period does not readily support independent validation, so the performance of multivariate linear algorithms was evaluated by $r^{2}$ fit, adjusted for the number of predictors. Our target time series exhibit minimal persistence (Figures 2(a) and 2(b)) yielding a degrees of freedom $\sim 30$. A predictive algorithm with $r^{2}$ fit $>0.50$ indicates that cost-effective tercile forecasts (above/normal/below) can be achieved. Forecast versus observed scatterplots were analyzed for slope, tercile hits, and outliers.

\section{Results}

3.1. Targets and Correlation Maps. The regression of rain and vegetation time series (Figures 2(a) and 2(b)) onto global fields of Ts, SLP, and U wind is calculated for the prescribed lead time, season, and area. The targets reflect biennial and decadal oscillations (cf. $[29,34]$ ) and a more coherent structure for rainfall than vegetation. Strangely, year-to-year fluctuations of MJJ rain correlate significantly with colocated MJJ vegetation ( 0.4) but not in ASO season. Many candidate predictors emerge in the correlation maps (cf. [23]), but only a few are needed to form multivariate algorithms for northern Amhara and southern Oromia zones.

For MJJ northern rainfall, the selected DJF predictors (Figures 3(a) and 3(b); Table 1(a)) are surface temperatures over northern Europe (with a coefficient of -0.38) and the central Indian Ocean $(-0.39)$ and $850 \mathrm{mb}$ zonal winds over the central Atlantic (-0.44) and South Indian Ocean (0.42). For ASO northern rainfall (Figures 3(c)-3(e)) the selected MAM predictors are surface temperature over Asia $(-0.45)$, $200 \mathrm{mb}$ zonal winds over the northwest Pacific (0.50), and $850 \mathrm{mb}$ zonal winds over western Europe (0.47) and east

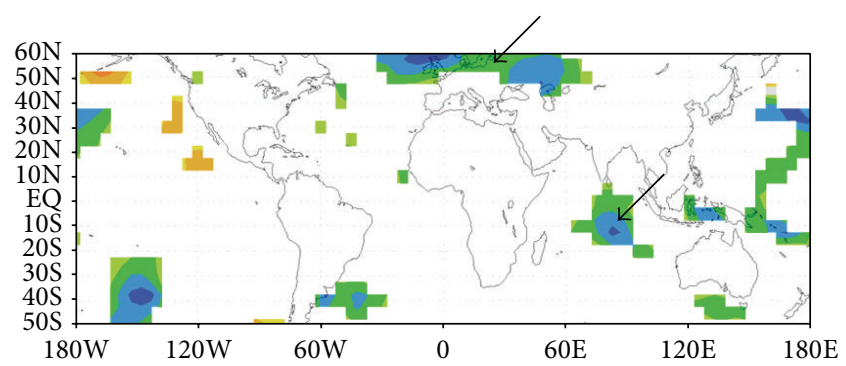

(a)

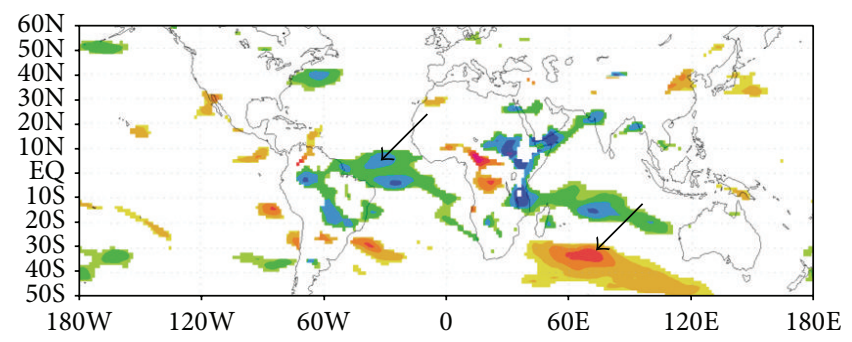

(b)

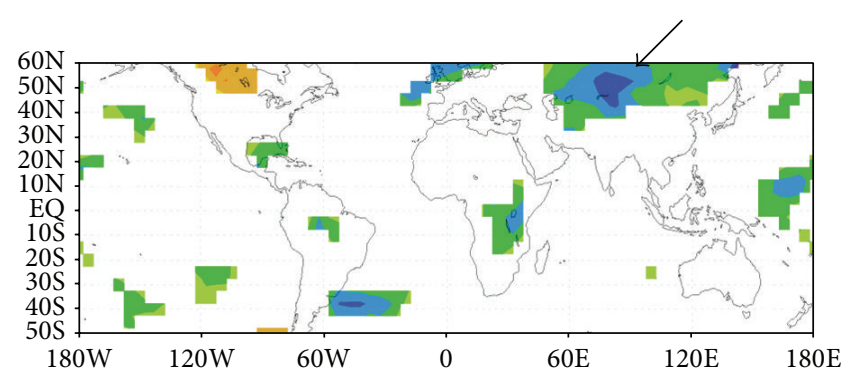

(c)

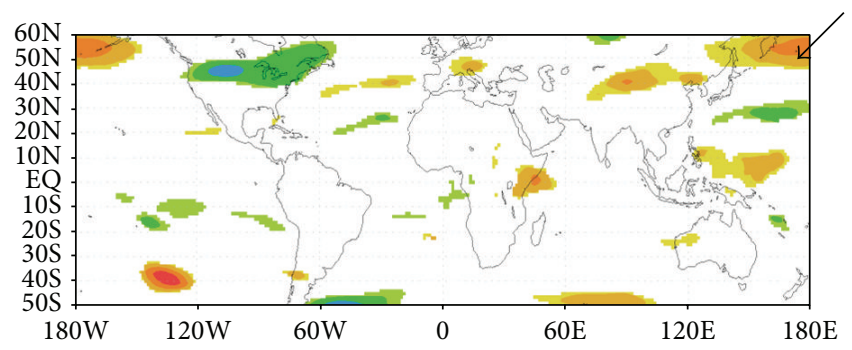

(d)

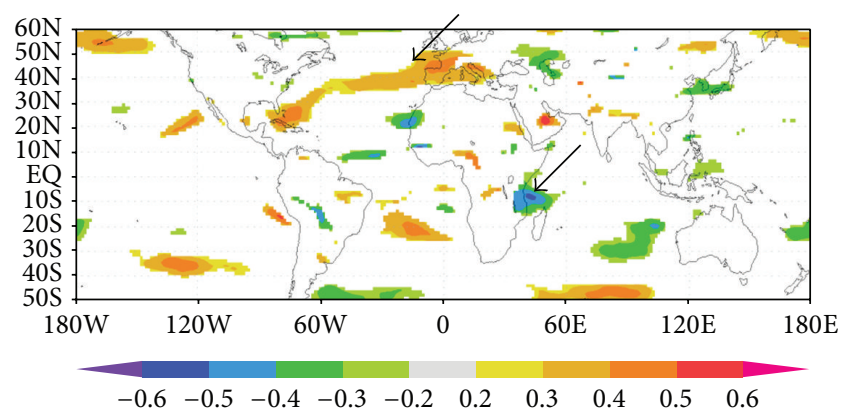

(e)

FIGURE 3: Correlation of MJJ northern rain with DJF predictors: (a) Ts and (b) $850 \mathrm{U}$ fields. Correlation of ASO northern rain with MAM predictors: (c) Ts, (d) $200 \mathrm{U}$, and (e) 850 U fields 1983-2012. Values below $80 \%$ significance are masked here and in Figures 4-6; arrows highlight predictors employed. 
TABLE 1: Multivariate predictors for (a) rain and (b) vegetation.

(a)

\begin{tabular}{lccc}
\hline Target & Predictor & Domain & Coefficient \\
\hline MJJ northern rain & Ts n Europe & $45 \mathrm{~N}-65 \mathrm{~N}, 40 \mathrm{~W}-70 \mathrm{E}$ & -0.38 \\
$r^{2}=0.51$ & Ts c Indian O & $20 \mathrm{~S}-10 \mathrm{~N}, 70 \mathrm{E}-95 \mathrm{E}$ & -0.39 \\
Offset $=0.01$ & $8 \mathrm{U}$ c Atlantic & $10 \mathrm{~S}-10 \mathrm{~N}, 60 \mathrm{~W}-10 \mathrm{~W}$ & -0.44 \\
\hline ASO northern rain & $8 \mathrm{U}$ s Indian O & $45 \mathrm{~S}-30 \mathrm{~S}, 40 \mathrm{E}-110 \mathrm{E}$ & -0.42 \\
$r^{2}=0.53$ & Ts Asia & $40 \mathrm{~N}-60 \mathrm{~N}, 50 \mathrm{E}-130 \mathrm{E}$ & -0.45 \\
Offset $=0.01$ & $2 \mathrm{U}$ nw Pacific & $45 \mathrm{~N}-60 \mathrm{~N}, 140 \mathrm{E}-160 \mathrm{~W}$ & 0.50 \\
& $8 \mathrm{U}$ w Europe & $35 \mathrm{~N}-50 \mathrm{~N}, 50 \mathrm{~W}-20 \mathrm{E}$ & 0.47 \\
MJJ southern rain & $8 \mathrm{U}$ e Africa & $15 \mathrm{~S}-0 \mathrm{~N}, 35 \mathrm{E}-55 \mathrm{E}$ & -0.45 \\
$r^{2}=0.49$, offset $=0.03$ & Ts n Europe & $45 \mathrm{~N}-60 \mathrm{~N}, 20 \mathrm{~W}-80 \mathrm{E}$ & -0.70 \\
ASO southern rain & $8 \mathrm{U}$ c Atlantic & $15 \mathrm{~S}-10 \mathrm{~N}, 70-20 \mathrm{~W}$ & -0.56 \\
$r^{2}=0.51$ & Ts se Atlantic & $20 \mathrm{~S}-0 \mathrm{~N}, 15 \mathrm{~W}-15 \mathrm{E}$ & -0.28 \\
Offset $=0.05$ & $2 \mathrm{U}$ s America & $32 \mathrm{~S}-15 \mathrm{~S}, 120 \mathrm{~W}-0 \mathrm{~W}$ & 0.21 \\
\hline
\end{tabular}

(b)

\begin{tabular}{lccc}
\hline Target $^{*}$ & Predictor & Domain & Coefficient \\
\hline ASO northern Veg & Ts sw Pacific & $30 \mathrm{~S}-12 \mathrm{~N}, 140 \mathrm{E}-170 \mathrm{E}$ & 0.59 \\
& SLP n Atlantic & $48 \mathrm{~N}-62 \mathrm{~N}, 80 \mathrm{~W}-0 \mathrm{~W}$ & 0.38 \\
$r^{2}=0.67$ & SLP s Indian O & $50 \mathrm{~S}-30 \mathrm{~S}, 65 \mathrm{E}-110 \mathrm{E}$ & -0.34 \\
& 2 U n Africa & $22 \mathrm{~N}-35 \mathrm{~N}, 30 \mathrm{E}-40 \mathrm{E}$ & -0.31 \\
MJJ southern Veg & Ts w Indian O & $18 \mathrm{~S}-18 \mathrm{~N}, 5 \mathrm{~W}-100 \mathrm{E}$ & -0.34 \\
$r^{2}=0.43$ & Ts se Pacific & $38 \mathrm{~S}-18 \mathrm{~S}, 110 \mathrm{~W}-75 \mathrm{~W}$ & -0.47 \\
ASO southern Veg & 2 U se Pacific & $32 \mathrm{~S}-15 \mathrm{~S}, 125 \mathrm{~W}-70 \mathrm{~W}$ & 0.28 \\
& Ts sw Atlantic & $50 \mathrm{~S}-32 \mathrm{~S}, 50 \mathrm{~W}-10 \mathrm{~W}$ & -0.26 \\
$r^{2}=0.62$ & SLP Europe & $40 \mathrm{~N}-60 \mathrm{~N}, 25 \mathrm{~W}-15 \mathrm{E}$ & -0.35 \\
& SLP s Indian O & $50 \mathrm{~S}-30 \mathrm{~S}, 60 \mathrm{E}-90 \mathrm{E}$ & -0.50 \\
\hline
\end{tabular}

${ }^{*} \mathrm{MJJ}$ northern omitted.

Africa (-0.45). For MJJ southern rainfall (Figures 4(a) and 4(b)), the selected DJF predictors are surface temperature over northern Europe $(-0.70)$ and $850 \mathrm{mb}$ zonal winds over the central Atlantic (-0.56). For ASO southern (GPCC6) rainfall (Figures $4(\mathrm{c})$ and $4(\mathrm{~d})$ ) the selected MAM predictors are surface temperature over the southeast Atlantic (-0.28) and $200 \mathrm{mb}$ zonal winds over South America (0.21) and the southwest Atlantic (-0.56). Arrows on the maps highlight their position, while Table 1(a) lists their domain. A key feature is negative Ts correlations in northern Eurasia (cf. Figures 3(a), 3(c), and 4(a)) indicating that a cold winterspring there precedes favourable Ethiopian rainfall. This signal is part of the Arctic Oscillation and its quasi-biennial circulation anomalies ([35-37]) that affect Ethiopia as outlined in Jury [23]. The correlation dipole over the southwest Atlantic (cf. Figure 4(c)) refers to an equatorward-displaced subtropical jet that plays a role in the ASO southern rain algorithm. The Pacific ENSO-PDO pattern of strengthened equatorial trade winds (Figure $4(\mathrm{~b})$ ) is not selected as a predictor.

Vegetation in the northern zone rises slowly after May (cf. Figure 1(b)) so its early season variability is not considered here. Maps for ASO northern vegetation (Figures 5(a)5(c)) point to the following MAM predictors are surface temperature over the southwest Pacific (0.59), sea level air pressure over the north Atlantic (0.38) and south Indian Ocean (-0.34), and the $200 \mathrm{mb}$ zonal wind over North Africa (-0.31). The later predictor suggests influence from the Arctic Oscillation (AO) and North Atlantic Oscillation (NAO). For MJJ southern vegetation (Figures 6(a) and 6(b)) the DJF predictors are surface temperature in the west Indian Ocean $(-0.34)$ and the southeast Pacific (-0.47), and $200 \mathrm{mb}$ zonal winds over the southeast Pacific (0.28). For ASO southern vegetation (Figures 6(c)-6(e)) the MAM predictors are surface temperature over the southwest Atlantic (-0.26), sea level air pressure over northern Europe $(-0.35)$ and the south Indian Ocean $(-0.50)$, and $200 \mathrm{mb}$ zonal winds over the northeast Pacific (-0.60). Table 1(b) lists their domains and arrows again identify their position. One signal which stands out is negative Ts correlations in the Indian Ocean north of 20S (cf. Figure 6(a)) that affect early summer vegetation in Oromia. Another feature is the slow westward shift of $200 \mathrm{mb}$ zonal wind signals in the eastern Pacific, indicative of poleward-displaced subtropical jets in both 


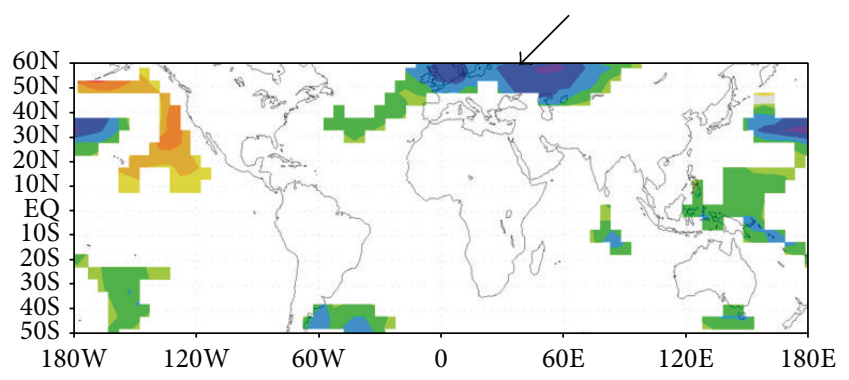

(a)

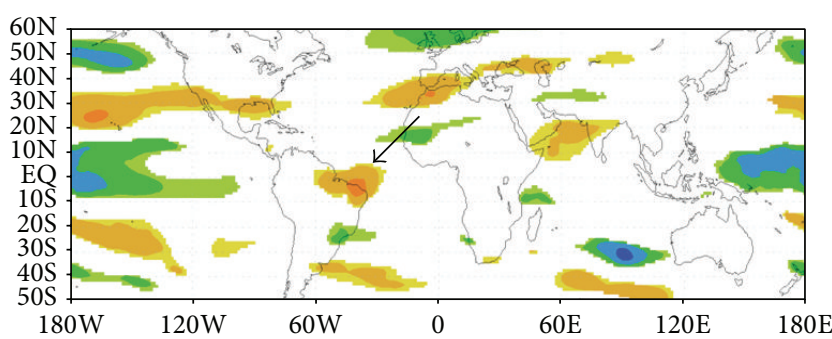

(b)

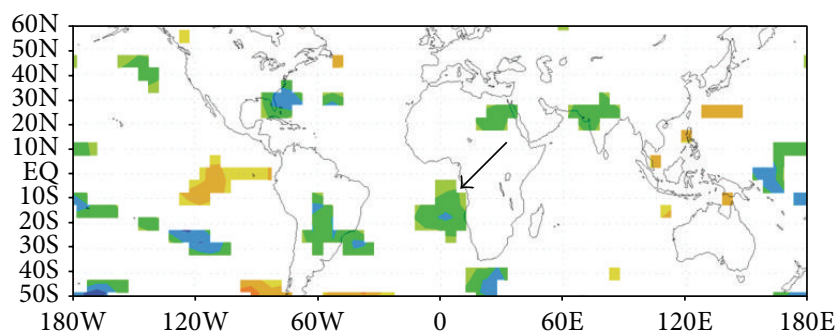

(c)

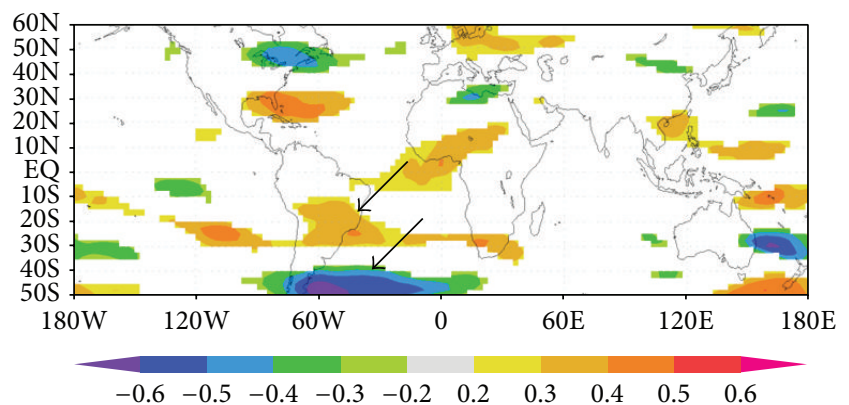

(d)

Figure 4: Correlation of MJJ southern rain with DJF (a) Ts and (b) 850 U fields 1983-2012. Correlation of ASO southern rain with MAM predictors: (c) Ts, and (d) $200 \mathrm{U}$ fields for GPCC6 rain 19812010.

hemispheres (cf. Figures 6(b) and 6(e)) consistent with ENSO-PDO.

3.2. Algorithm Performance. Scatterplots of the multivariate algorithms are given in Figure 7 for Rain and Figure 8 for Vegetation, and Tables 1(a) and 1(b) lists the $r^{2}$ fit. For northern rainfall the predictive algorithm achieves $r^{2}$ of 0.51 in early summer and 0.53 in late summer, a satisfactory result. The multivariate algorithm for southern rainfall

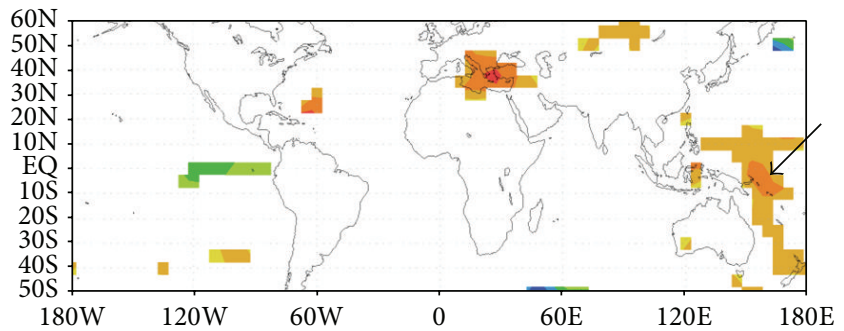

(a)

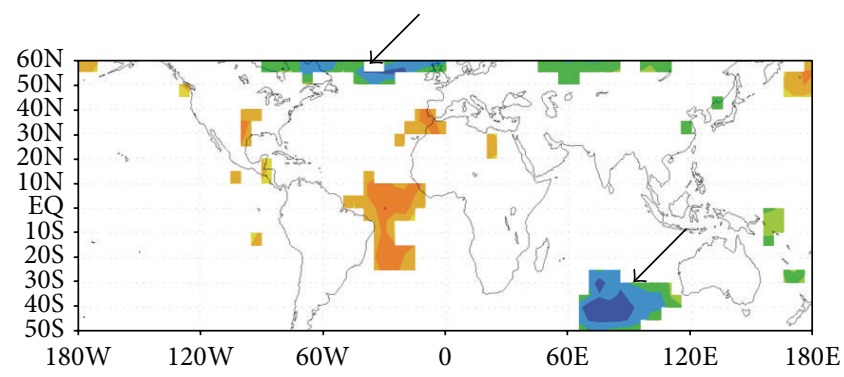

(b)

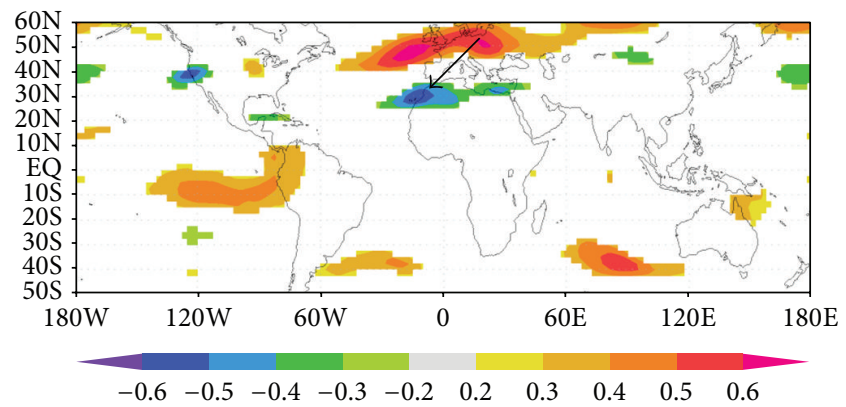

(c)

FIGURE 5: Correlation of ASO northern vegetation with MAM (a) Ts, (b) SLP, and (c) 200 U fields 1981-2006.

exhibits similar values of 0.49 and 0.51 for MJJ and ASO seasons, respectively. Curiously ARC2 and GPCC6 rainfall diverge over the southern area in late summer, with the later exhibiting higher amounts (cf. Figure 1(b)) and greater predictability. The scatterplots of predicted and observed rainfall show dispersion within the normal tercile and tend to taper favourably toward the extremes. Outliers are noted more in the south, wherein the algorithm yields neutral forecasts of early summer rains in 1996 (obs $=2.1 \sigma$ ) and in 2003 (obs $=-1.2 \sigma$ ). The algorithm for southern rainfall underpredicts late summer rains in 1988 (obs $=2.4 \sigma$ ). The results suggest that statistical predictions in March for MJJ rainfall and in June for ASO rainfall should be reliable.

The multivariate algorithms for vegetation exhibit low skill in early summer $\left(r^{2}=0.43\right.$ south) possibly due to the erratic nature of warm spells. A substantially better fit is achieved in late summer when the multivariate algorithm for northern vegetation reaches 0.67 , while southern vegetation $r^{2}$ is 0.62 . As NDVI follows crop production [23] and grazing yields, its predictability is most fortunate. The scatterplots for vegetation forecasts display correct tercile "hits" in late 


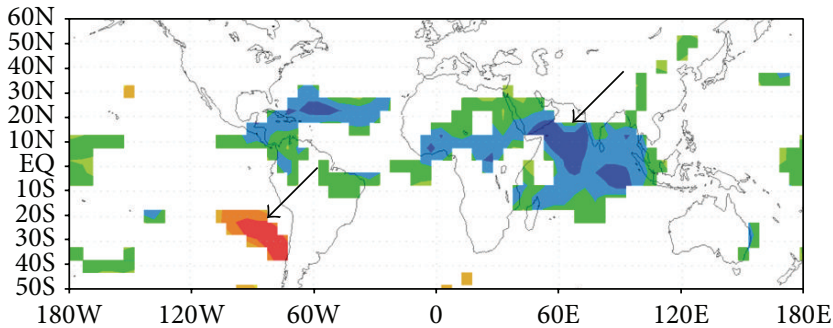

(a)

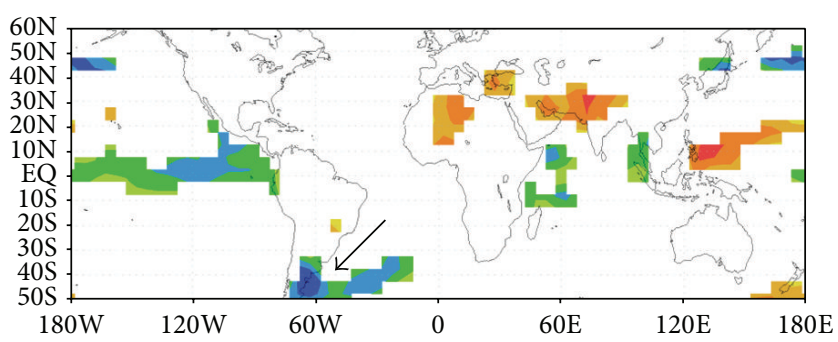

(c)

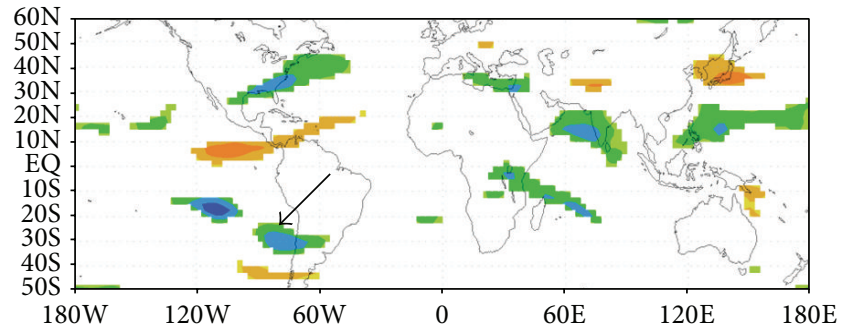

(b)

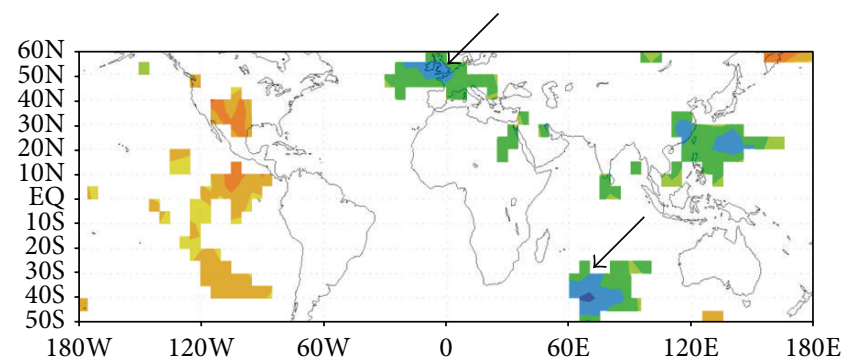

(d)

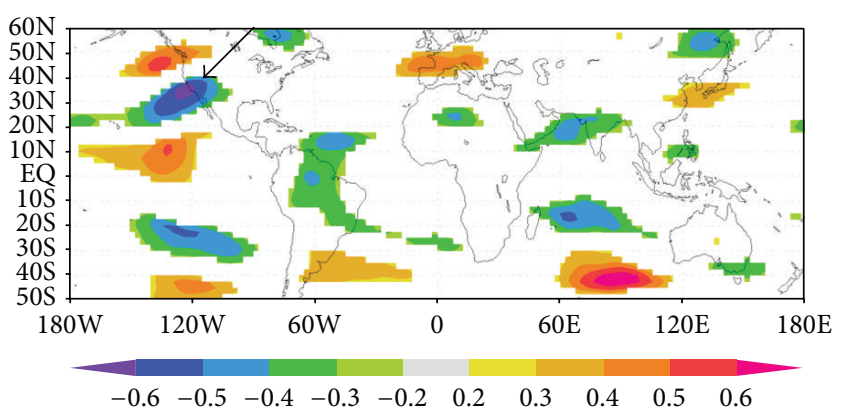

(e)

FIGURE 6: Correlation of MJJ southern vegetation with DJF (a) Ts and (b) 200 U fields. Correlation of ASO southern vegetation with MAM (c) Ts, (d) SLP, and (e) 200 U fields 1981-2006.

summer particularly in the northern zone, with drought underpredicted in 1991 (obs $=-1.9 \sigma$ ). The algorithm for late summer southern vegetation exhibits three neutral forecasts when the corresponding observations were in the upper or lower tercile. One outlier (false alarm) is noted for early summer southern vegetation, when drought was predicted in 2005 but neutral conditions ensued. The $r^{2}$ fit of our statistical model forecasts is almost triple those reported by Wang and Fan [16] for northern hemisphere summer rainfall.

\section{Concluding Discussion}

In this study, statistical algorithms to predict rainfall and vegetation over Amhara and Oromia, Ethiopia were formulated. The target rainfall derive from high quality ARC2 and GPCC6 reanalysis that diverge slightly in the southern zone in late summer (cf. Figure 1(b)). Correlation maps were made with respect to Ts, SLP, and $200 / 850 \mathrm{mb}$ zonal winds which identified predictor-target relationships. From Table 1, Ts over Eurasia was the most influential predictor of rainfall (cold-favourable), followed by $850 \mathrm{mb}$ zonal winds over the
Atlantic (easterly-favourable), Ts over the tropical Indian Ocean (cold-favourable), and SLP over the south Indian Ocean (low-favourable). Predictors were selected evenly from the Atlantic, Indian, and Pacific basins, but ENSO-PDO signals were less influential (cf. Figures 4(b) and 6(e); w.r.t. southern vegetation). The rain targets selected zonal wind eight times, while the vegetation targets selected air pressure five times. After step-wise regression, algorithms for early and late season rainfall exhibited a consistent fit of $\sim 0.50$, while those for vegetation reached $\sim 0.65$ in late summer. Tercile hit rates exceeded two-thirds and false alarms were below onethird. How can our results be applied?

Ethiopia currently experiences food deficits because of low resource inputs, high population density, and variable climate. Shortfalls can be overcome with scientific information and practical engineering solutions [8]. Our climate predictions will be extended using crop yield simulators and formulated into coherent advice to collective decisionmakers/resource managers and individual investors/farmers. Mitigating actions will be suggested by agricultural extension services, with feedback from their network of cultivators dealing with impacts. 


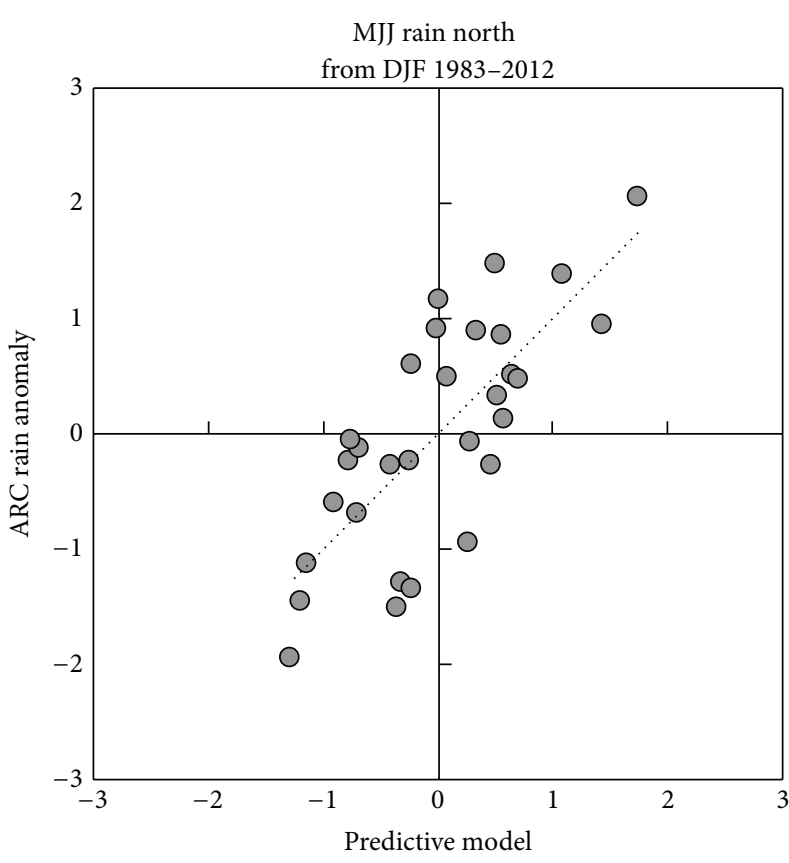

(a)

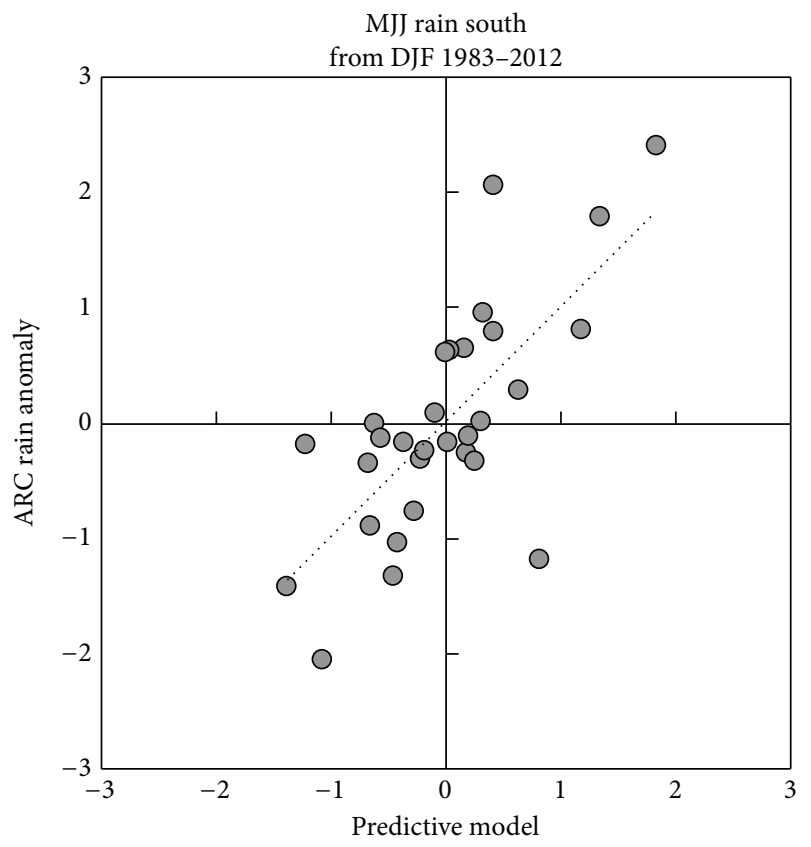

(c)

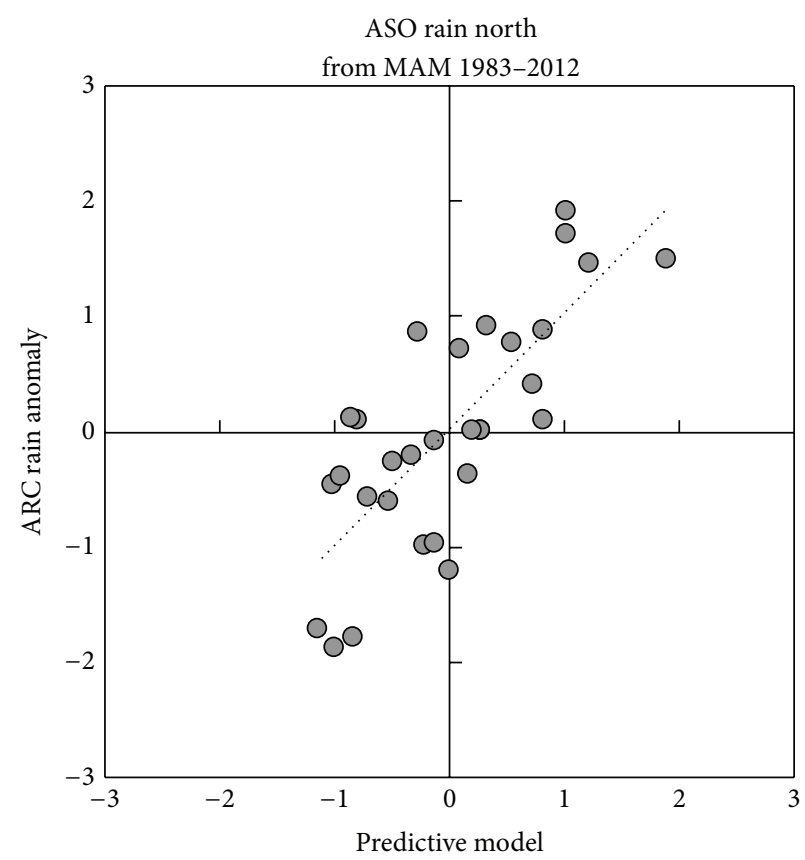

(b)

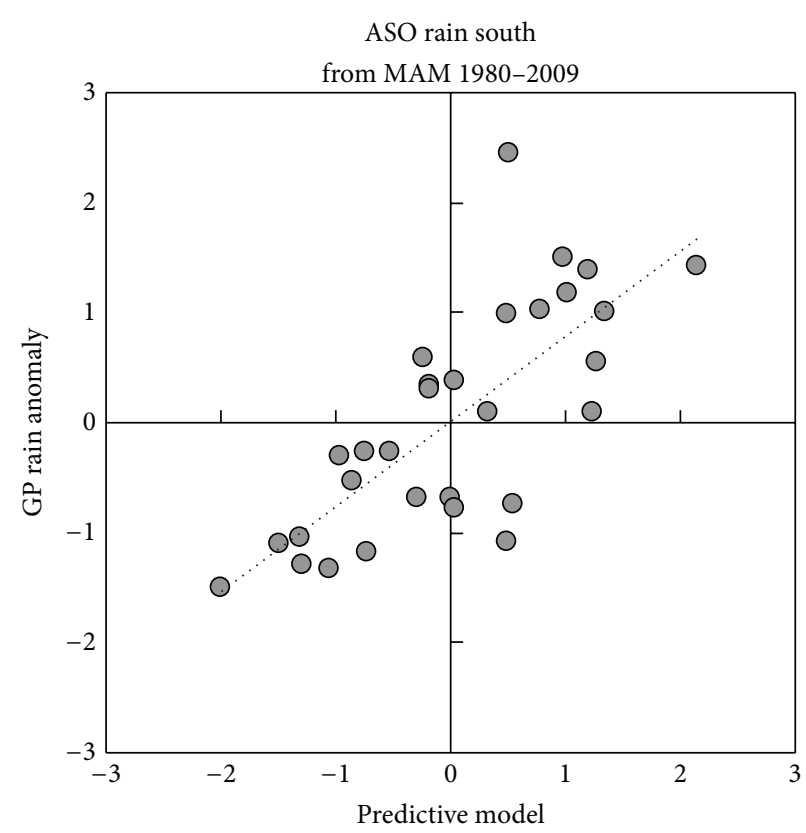

(d)

FIGURE 7: Scatterplots of predicted and observed rainfall according to Table 1(a). Southern ASO represented by GPCC6 rain; others are ARC2. Linear regression lines are applied.

We have sought to enhance our predictive capacity by statistically analyzing how surface temperature and pressure anomalies affect the overlying zonal circulation and tropical convection. The predictability of targeted resources is gratifying and highlights the ascendancy of extratropical signals (AO) and weakness of ENSO influence. Seasonal forecasts of early and late summer rainfall and vegetation over Ethiopia based on DJF and MAM predictors will provide the necessary lead time for strategic decisions to mitigate adverse impacts or take advantage of favourable weather. Processes underlying the apparent skill of extratropical predictors need to be tested via coupled ensemble model simulations. Further work is recommended by extending the predictor search to the subsurface oceans and meridional winds and by consideration of targets such as air temperature, evaporation, and streamflow. 


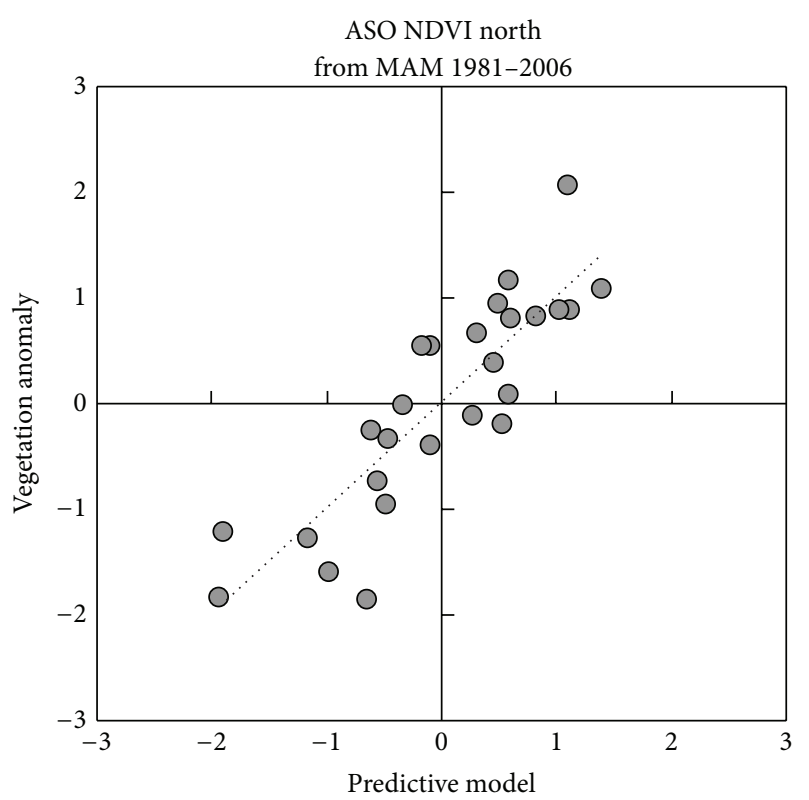

(a)

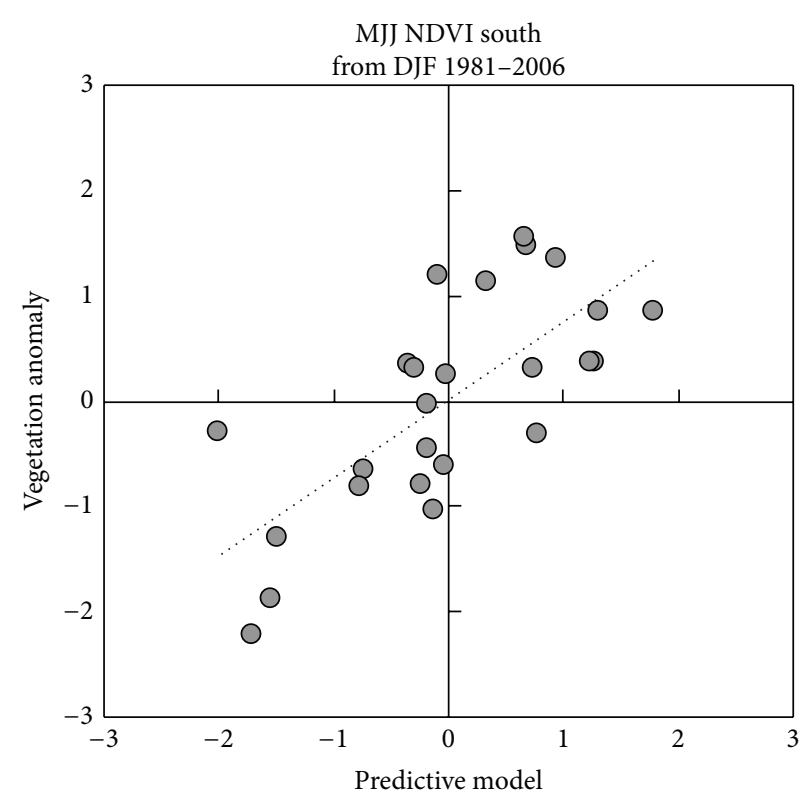

(b)

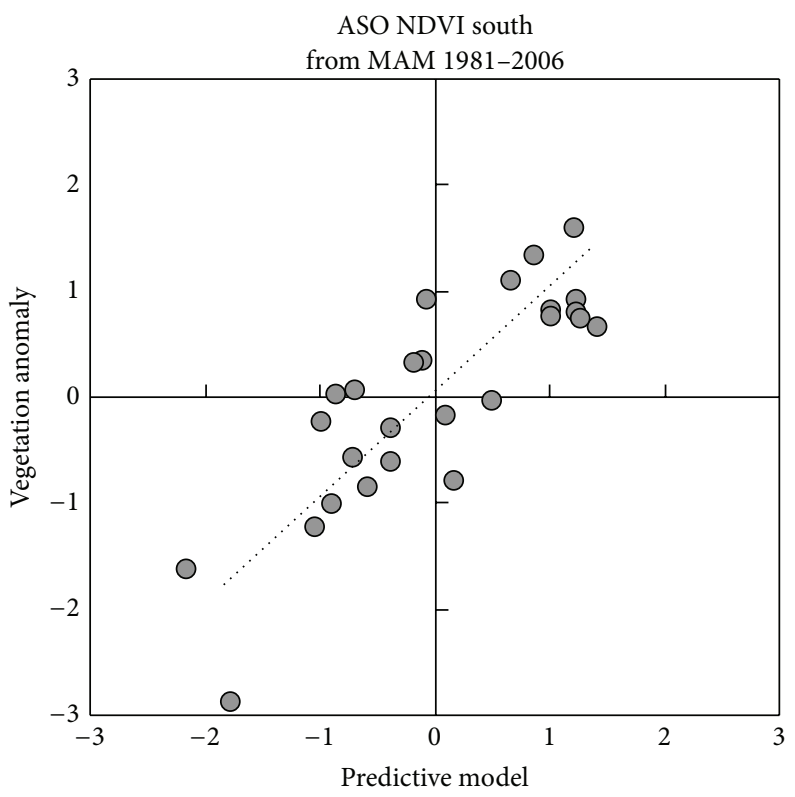

(c)

FIGURE 8: Scatterplots of predicted and observed NDVI vegetation according to Table 1(b), with northern MJJ season omitted.

\section{Conflict of Interests}

The author declares that there is no conflict of interests regarding the publication of this paper.

\section{Acknowledgments}

This study is part of a Rockefeller Foundation Project with the Ethiopian Institute for Agriculture Research, Melkassa supported by F. Getachew, A. Shimeles, and G. Mamo.

\section{References}

[1] FAO, State of Food Insecurity in the World 2012, Food and Agriculture Organisation, Rome, Italy, 2013.

[2] M. H. Glanz, R. W. Katz, and N. Nicholls, Teleconnection Linking Worldwide Climate Anomalies: Scientific Basis and Societal Impact, Cambridge University Press, Cambridge, UK, 1991.

[3] A. D. Moura and E. S. Sarachik, "Seasonal-to-interannual climate prediction and applications: new institutions, new possibilities," WMO Bulletin, vol. 46, no. 4, pp. 342-347, 1997. 
[4] WCRP, A Strategy for Climate Research in Africa, vol. 29 of ICPO Publication Series, World Climate Research Programme, CLIVAR. WRCP Report 16/1999, 1999.

[5] H. Meinke and Z. Hochman, "Using seasonal climate forecasts to manage dryland crops in northern Australia: experiences from the 1997/98 seasons," in Applications of Seasonal Climate Forecasting in Agricultural and Natural Ecosystems: The Australian Experience, G. L. Hammer, N. Nicholls, and C. Mitchell, Eds., pp. 149-160, Kluwer Academic Publishers, Dordrecht, The Netherlands, 2000.

[6] M. R. Jury, "Economic impacts of climate variability in South Africa and development of resource prediction models," Journal of Applied Meteorology, vol. 41, no. 1, pp. 46-55, 2002.

[7] C. Sadoff, "Can water resources undermine development in Ethiopia?" Agricultural and Rural Development Notes, World Bank, vol. 18, pp. 1-4, 2006.

[8] L. Goddard, Y. Aitchellouche, W. Baethgen et al., "Providing Seasonal-to-interannual climate information for risk management and decision-making," in Procedia Environmental Sciences, vol. 1, pp. 81-101, September 2009.

[9] W. B. White and Y. M. Tourre, "Global SST/SLP waves during the 20th century," Geophysical Research Letters, vol. 30, no. 12, pp. 53-57, 2003.

[10] M. R. Jury and B. Huang, "The Rossby wave as a key mechanism of Indian Ocean climate variability," Deep-Sea Research I, vol. 51, no. 12, pp. 2123-2136, 2004.

[11] A. Yeshanew and M. R. Jury, "North African climate variability. Part 2: tropical circulation systems," Theoretical and Applied Climatology, vol. 89, no. 1-2, pp. 37-49, 2007.

[12] Z. T. Segele, P. J. Lamb, and L. M. Leslie, "Seasonal-tointerannual variability of Ethiopia/horn of Africa monsoon. Part I: associations of wavelet-filtered large-scale atmospheric circulation and global sea surface temperature," Journal of Climate, vol. 22, no. 12, pp. 3396-3421, 2009.

[13] O. Ndiaye, M. N. Ward, and W. M. Thiaw, "Predictability of seasonal Sahel rainfall using GCMs and lead-time improvements through the use of a coupled model," Journal of Climate, vol. 24, no. 7, pp. 1931-1949, 2011.

[14] P. Oettli, B. Sultan, C. Baron, and M. Vrac, "Are regional climate models relevant for crop yield prediction in West Africa?" Environmental Research Letters, vol. 6, no. 1, Article ID 014008, 2011.

[15] M. R. Jury, "Evaluation of coupled model forecasts of Ethiopian highlands summer climate," in review, 2013.

[16] H. Wang and K. Fan, "A new scheme for improving the seasonal prediction of summer precipitation anomalies," Weather and Forecasting, vol. 24, no. 2, pp. 548-554, 2009.

[17] C. S. Bretherton, C. Smith, and J. M. Wallace, "An intercomparison of methods for finding coupled patterns in climate data," Journal of Climate, vol. 5, pp. 541-560, 1992.

[18] A. G. Barnston, "Linear statistical short-term climate predictive skill in the Northern Hemisphere," Journal of Climate, vol. 7, pp. 1513-1564, 1994.

[19] R. Vautard, G. Plaut, R. Wang, and G. Brunet, "Seasonal prediction of North American surface air temperatures using space-time principal components," Journal of Climate, vol. 12, no. 2, pp. 380-394, 1999.

[20] P. Camberlin, S. Janicot, and I. Poccard, "Seasonality and atmospheric dynamics of the teleconnection between African rainfall and tropical sea-surface temperature: Atlantic vs. ENSO," International Journal of Climatology, vol. 21, no. 8, pp. 973-1005, 2001.
[21] D. Korecha and A. G. Barnston, "Predictability of JuneSeptember rainfall in Ethiopia," Monthly Weather Review, vol. 135, no. 2, pp. 628-650, 2007.

[22] M. R. Jury, "Climatic factors modulating Nile River flow," in Nile River Basin Part IV, A. M. Melesse, Ed., pp. 267-280, Springer, 2011.

[23] M. R. Jury, "Ethiopian highlands crop-climate prediction 19792009," Journal of Applied Meteorology and Climatology, vol. 52, pp. 1116-1126, 2013.

[24] N. S. Novella and W. M. Thiaw, "African rainfall climatology version 2 for famine early warning systems," Journal of Applied Meteorology and Climatology, vol. 52, pp. 588-606, 2013.

[25] U. Schneider, T. Fuchs, A. Meyer-Christoffer, and B. Rudolf, Global Precipitation Analysis Products of the GPCC, Global Precipitation Climatology Centre Rep., 2008.

[26] U. Schneider, A. Becker, P. Finger, A. Meyer-Christoffer, M. Ziese, and B. Rudolf, "GPCC's new land surface precipitation climatology based on quality-controlled in situ data and its role in quanti-fying the global water cycle," Theoretical and Applied Climatology, vol. 115, no. 1-2, pp. 15-40, 2014.

[27] C. J. Tucker, J. E. Pinzon, M. E. Brown et al., "An extended AVHRR 8-km NDVI data set compatible with MODIS and SPOT vegetation NDVI data," International Journal of Remote Sensing, vol. 26, pp. 4485-5598, 2005.

[28] M. Jury, H. Rautenbach, M. Tadross, and A. Philipp, "Evaluating spatial scales of climate variability in sub-Saharan Africa," Theoretical and Applied Climatology, vol. 88, no. 3-4, pp. 169177, 2007.

[29] M. R. Jury, "Ethiopian decadal climate variability," Theoretical and Applied Climatology, vol. 101, no. 1, pp. 29-40, 2010.

[30] T. M. Smith, R. W. Reynolds, T. C. Peterson, and J. Lawrimore, "Improvements to NOAA's historical merged land-ocean surface temperature analysis (1880-2006)," Journal of Climate, vol. 21, no. 10, pp. 2283-2296, 2008.

[31] R. Allan and T. Ansell, "A new globally complete monthly historical gridded mean sea level pressure dataset (HadSLP2): 1850-2004," Journal of Climate, vol. 19, no. 22, pp. 5816-5842, 2006.

[32] S. Saha, S. Moorthi, H.-L. Pan et al., "The NCEP climate forecast system reanalysis," Bulletin of the American Meteorological Society, vol. 91, pp. 1015-1057, 2010.

[33] M. M. Rienecker, M. J. Suarez, R. Gelaro et al., "MERRA: NASA's modern-era retrospective analysis for research and applications," Journal of Climate, vol. 24, pp. 3624-3648, 2011.

[34] P. Chang, L. Ji, and H. Li, "A decadal climate variation in the tropical Atlantic Ocean from thermodynamic air-sea interactions," Nature, vol. 385, no. 6616, pp. 516-518, 1997.

[35] J. Cohen and D. Entekhabi, "Eurasian snow cover variability and Northern Hemisphere climate predictability," Geophysical Research Letters, vol. 26, no. 3, pp. 345-348, 1999.

[36] G. Gong, D. Entekhabi, and J. Cohen, "Orographic constraints on a modeled Siberian snow-tropospheric-stratospheric teleconnection pathway," Journal of Climate, vol. 17, no. 6, pp. 11761189, 2004.

[37] R. J. Allen and C. S. Zender, "Forcing of the arctic oscillation by eurasian snow cover," Journal of Climate, vol. 24, no. 24, pp. 6528-6539, 2011. 

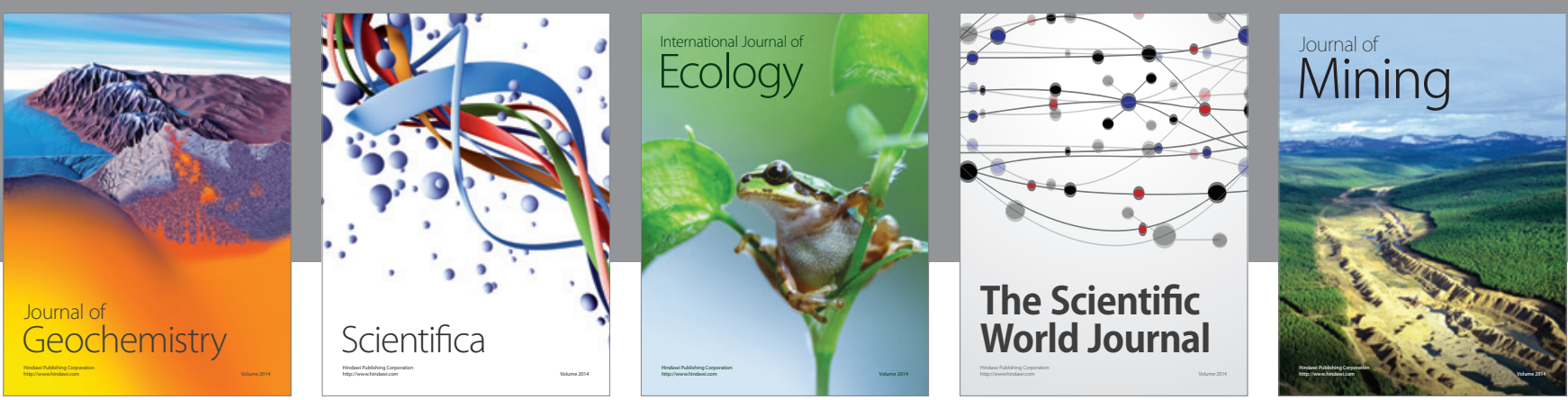

The Scientific World Journal
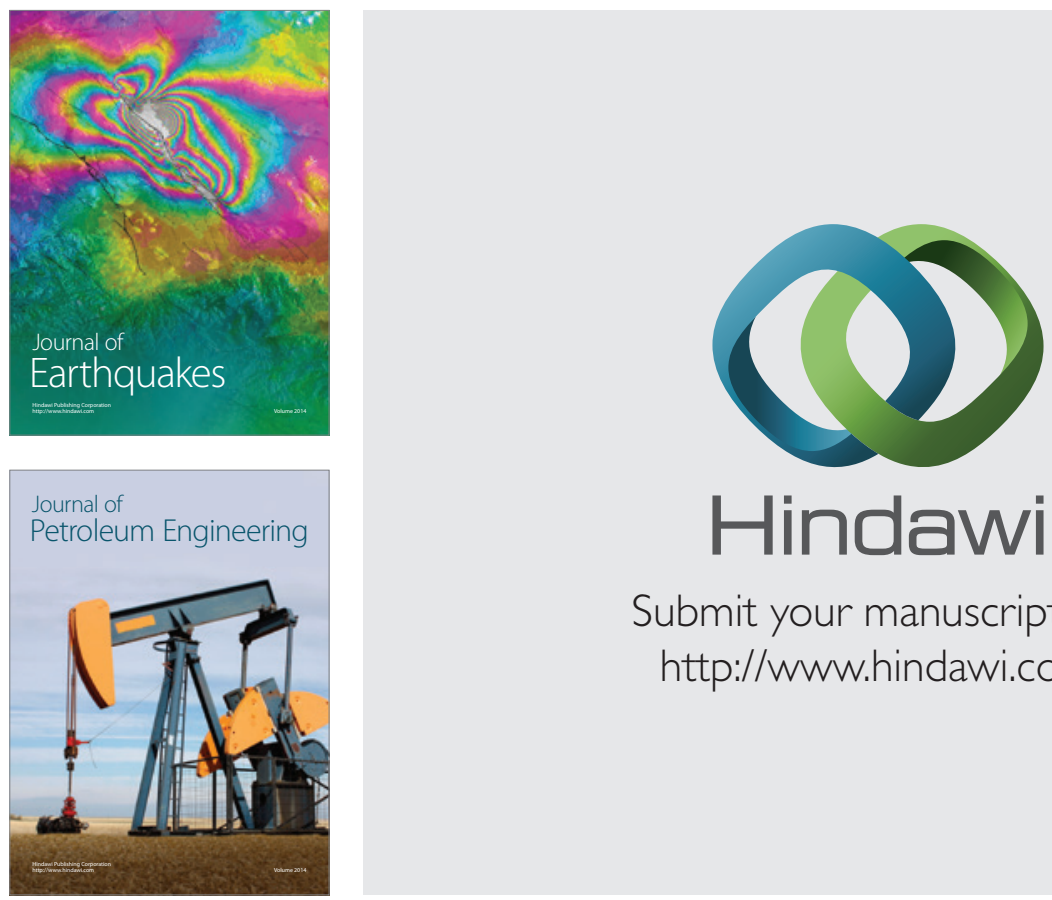

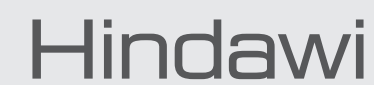

Submit your manuscripts at

http://www.hindawi.com
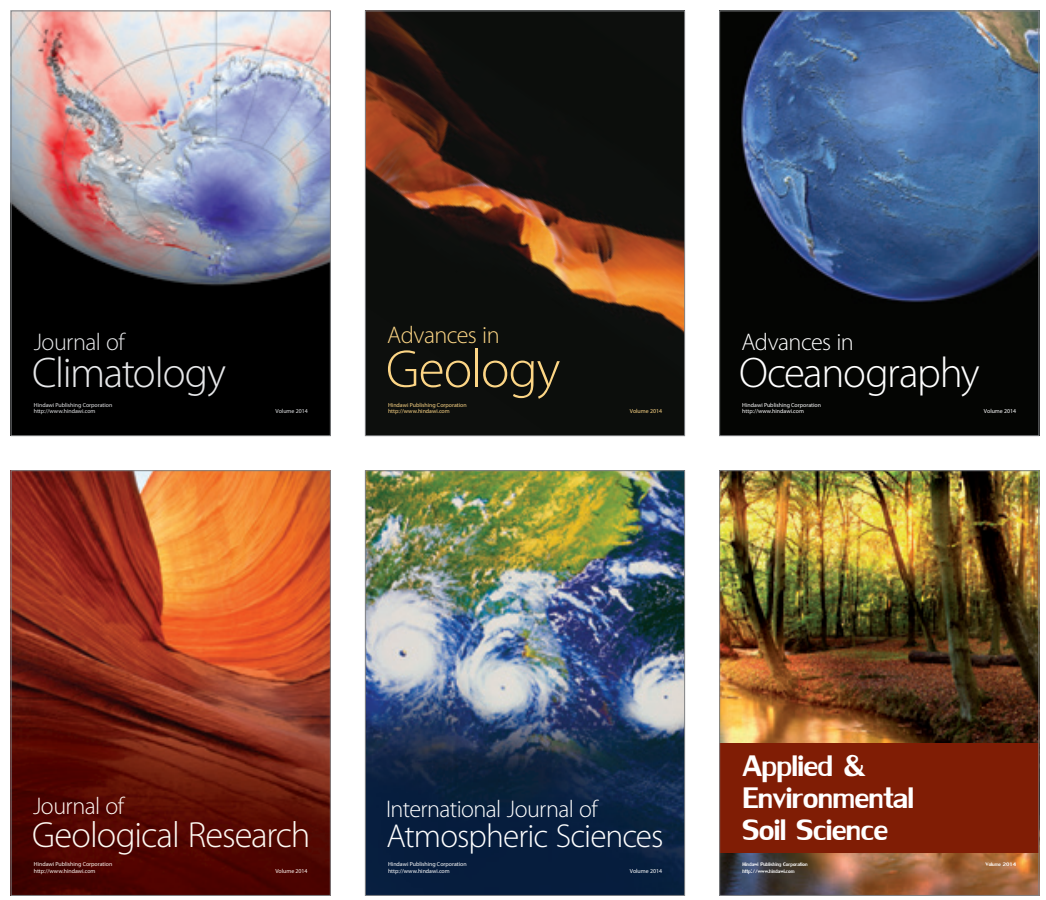
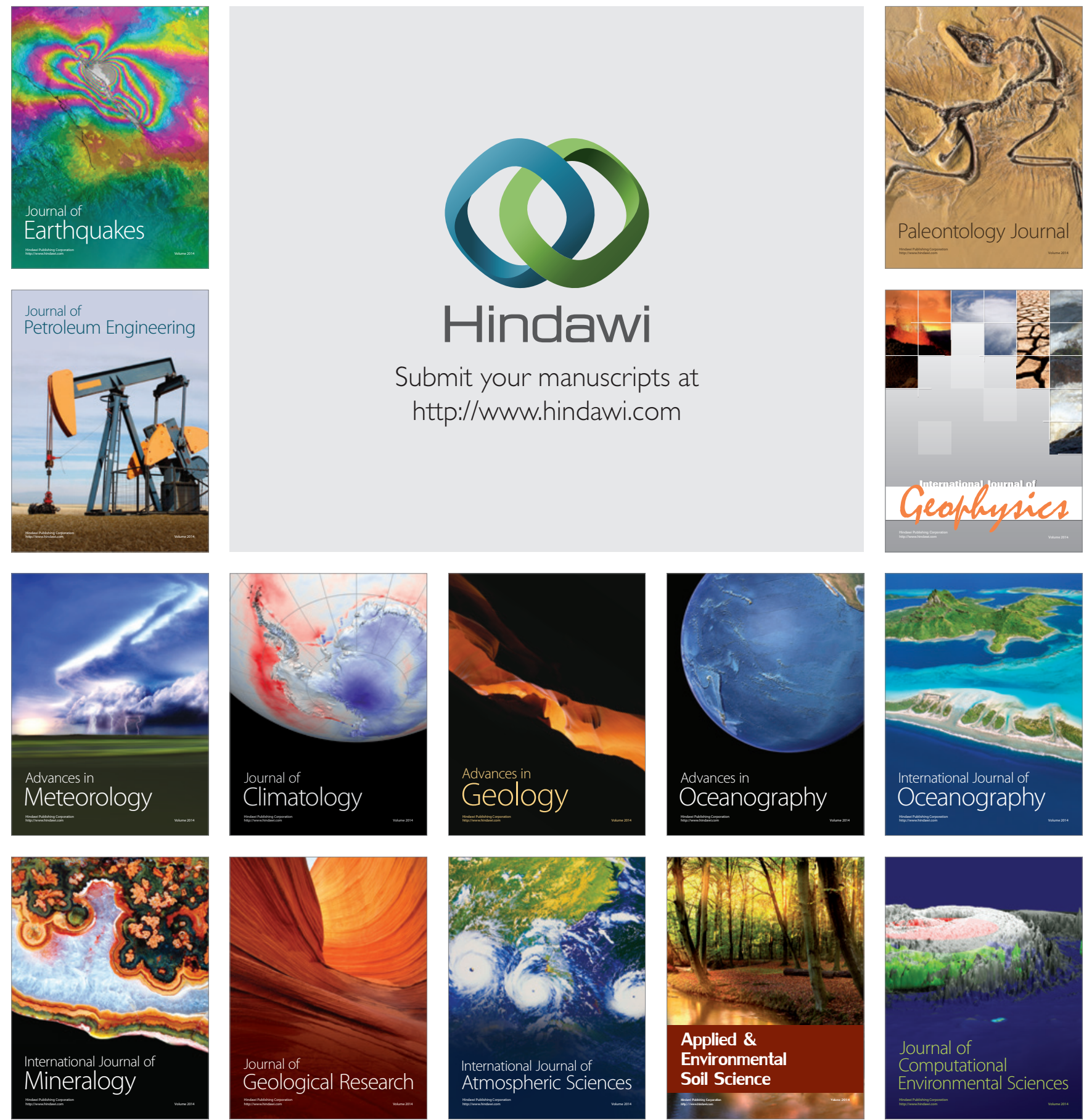